\title{
Medical Necessity Standards for Mental Health Parity in California
}

\section{Navita Kalair ${ }^{1}$, Clio Korn ${ }^{2}$, Larissa J Maier ${ }^{3}$, Thomas Pospiech $^{4,5}$, Neiloy R Sircar6, Trisha Vaidyanathan ${ }^{7}$}

1 University of California, San Francisco, Department of Preventative and Restorative Dental Sciences, San Francisco, CA

2University of California, San Francisco, Department of Psychiatry and Behavioral Sciences, San Francisco, CA 3University of California, San Francisco, Department of Clinical Pharmacy, San Francisco, CA

${ }^{4}$ University of Michigan, Graduate Program in Chemical Biology, Ann Arbor, MI

5University of California, San Francisco, Biochemistry and Biophysics, Institute for Neurodegenerative Diseases, San Francisco, CA

6University of California, San Francisco, Center for Tobacco Control Research and Education, San Francisco, CA

7University of California, San Francisco, Neuroscience Graduate Program, San Francisco, CA http://doi.org/10.38126/JSPG170208

Corresponding Author: trisha.vaidyanathan@ucsf.edu

Keywords: mental health; health care; medical necessity; mental health parity; California

Executive Summary: One in six adults in California experience a mental illness, but up to 63\% may not receive mental health services (California Health Care Foundation 2018). The treatment gap is even larger for people with substance use disorders (SUDs), and lack of treatment can lead to increased rates of suicide, homelessness, and incarceration (Weiner 2019a). Mental health parity laws require health insurance companies to cover mental and physical health services equally. These laws have helped reduce individual costs for mental health and SUD treatment (Ettner et al. 2016), but recent reports emphasize that California has not yet achieved full parity (Davenport, Gray, and Melek 2019; Parity Track 2019a; Weiner $2019 b)$. Insurers commonly circumvent parity laws when denying behavioral health claims due to lack of "medical necessity," a determination created by the insurer that lacks sufficient government oversight. We identify three issues with definitions of medical necessity and propose policy solutions that will 1) align medical necessity criteria with current scientific and medical standards, 2) regulate the influence of financial self-interest in assessing medical necessity, and 3) improve transparency of medical necessity criteria to clients. These solutions will help increase access to equitable, client-centered behavioral health care in California.

\section{Introduction}

Both federal and California mental health parity laws require that behavioral and physical health conditions be covered equally. Yet, recent reports highlight that the gulf between mental and physical health coverage in California is worsening (Davenport, Gray, and Melek 2019; Parity Track 2019a). Insufficient coverage means that mental health services are often only provided once symptoms have reached crisis levels, frequently either at emergency centers or in state prisons, and at great cost to taxpayers (Weiner 2019a; Stanford Justice Advocacy Project 2017; Jarkon 2020). In its 2019 Wit et al. v. United Behavioral Health decision, the District Court of Northern California noted disparities in accessing and receiving coverage for mental health needs, citing multiple instances of noncompliance with existing laws and generally accepted standards of care (Erman and Kolsrud 2019). 
Governor Newsom and his top mental health advisor have emphasized the need for a review of parity enforcement, including in the provisional 2020 budget (Weiner 2019b; Office of the Governor 2020). The California Assembly recently passed a resolution (ACR-98, 2019) calling for relevant state agencies to ensure that insurers comply with parity laws. Additionally, in January 2020 two Senate bills (SB854, SB-855) were introduced that aim to expand the treatments covered under parity laws and reduce barriers to accessing treatment (The Kennedy Forum 2020). In light of these recent efforts and of increased mental health needs related to the COVID-19 pandemic and calls for justice in policing, it is imperative to develop policy addressing mental health parity.

Many factors contribute to lack of mental health parity in California, including insufficient enforcement, a shortage of mental health care providers, and a decentralized mental health care system (Weiner 2019a). While there has been some success in enforcing parity through "Quantifiable Treatment Limits" (such as co-pays and visit limits), it remains challenging to regulate the use of "NonQuantitative Treatment Limits," particularly medical necessity determinations. Criteria for necessity are currently defined by insurers and are notoriously variable and inconsistent. This is reflected in higher rates of private insurer claim denials due to lack of medical necessity for mental health (29\%) and SUD services $(18 \%)$ when compared to physical medical care (14\%) (National Alliance on Mental Illness 2015). Such denials contribute to clients seeking outof-network care for mental health symptoms and SUDs at higher rates than for physical conditions: Californians are 4-8 times more likely to go out-ofnetwork for mental health office visits (Davenport, Gray, and Melek 2019).

Addressing limitations and inconsistencies in medical necessity definitions is critical to achieving mental health parity in California. We identify three major issues with how medical necessity in behavioral health care is determined, assessed, and communicated, and propose policy solutions to address each of them.
II. Issue 1: Medical necessity criteria do not align with current scientific and medical standards

Scientists and clinicians have learned a great deal about mental illness since the passage of the Mental Health Parity Act in 1996. The California Mental Health Parity Act (1999) specified nine severe mental illnesses covered under parity in California but excluded SUDs. Later, the federal Mental Health Parity and Addiction Equity Act (2008) expanded parity to cover treatment for SUDs. However, other mental illnesses that can significantly affect peoples' lives, such as generalized anxiety disorder, remain uncovered by parity law in California. Even for covered illnesses, insurers are not required to consult mental health professionals or current medical standards in determining "medical necessity," resulting in a gap between current scientific understanding and the coverage available for mental health care services (Rosenbaum et al. 2003).

i. Policy recommendation: Medical necessity criteria must be determined by licensed behavioral health professionals in accordance with current scientific and medical guidelines.

If an insurer offers mental health benefits, it must defer to licensed behavioral health professionals to define and evaluate its medical necessity criteria. Medical necessity criteria should align with current understanding of mental illness and SUDs. Illinois recently passed legislation along these lines (SB1707,2018 ) that designated the latest version of the Diagnostic Statistical Manual of Mental Disorders from the American Psychiatric Association as a reference for general mental illnesses, and the American Society of Addiction Medicine Criteria as a reference for serious mental illnesses and SUDs. Notably, Colorado, New Jersey, and Tennessee also recently passed legislation addressing parity (Roy 2019; Parity Track 2019b; Parity Track 2019c).

\section{Advantages}

Aligning medical necessity criteria with current medical standards would expand the number of mental health conditions covered by insurance, and clients would be able to access covered care before their symptoms reach crisis levels, resulting in better and less costly care overall (Weiner 2019b). Using licensed behavioral health professionals would also ensure that the appropriate health experts are reviewing claims. 


\section{Disadvantages}

Insurers might decide to not offer mental health benefits to avoid having to cover additional services. They might also pass on the cost of the additional staff required to meet these standards to clients. If insurers did provide mental health benefits for a broader range of conditions, the mental health care system might experience a large influx of people seeking treatment and be pushed beyond its capacity. Policies to improve medical necessity determinations must therefore be accompanied by policies to expand the behavioral health care workforce.

\section{Issue 2: Cost considerations inappropriately influence determinations of medical necessity}

Violations of mental health parity often result from insurance companies attempting to reduce costs. Currently, insurers use a complex, multi-dimensional approach in determining medical necessity that includes assessing the cost of the treatment (Rosenbaum et al. 2003). For example, insurers can use a "fail-first" strategy, in which the insurer will cover a more expensive treatment only after the client has first failed at a cheaper treatment (Dangor 2019). Few regulations exist to limit insurers from acting out of financial self-interest even where doing so might affect client well-being. In the Wit case, the court found that the medical necessity guidelines created by United Behavioral Health were "infected" by the financial incentives of the company (Erman and Kolsrud 2019). Regulators and clients lack sufficient transparency to ascertain how insurers assess medical necessity for individual cases and the extent to which cost is considered. Lack of transparency advantages insurers at the expense of clients and can allow financial self-interest to overly influence treatment coverage decisions.

i. Policy recommendation: Require that each claim denial be accompanied by a detailed explanation of why the treatment was not considered medically necessary.

Insurers should be required to provide explanations for each claim denial detailing how the decision was determined. This disclosure would address each factor, including cost, used to assess the claim and should reference what steps were taken to consider the provider's recommendations for the client. This explanation should be made available promptly to both the client and provider.

\section{Advantages}

This proposal would increase transparency in how insurers determine medical necessity and how provider-recommended treatments are reviewed. Decision statements would provide clarity to providers, clients, and their families, who are often frustrated by their lack of understanding around why a claim was denied (National Alliance on Mental Illness 2015). It would also give providers a better understanding of how their recommendations for clients are considered by insurance companies and would create a record of medical necessity practices used by insurers. This record could help disincentivize the prioritization of financial selfinterest over other factors as described in the Wit case (Erman and Kolsrud 2019). Furthermore, such a record would provide evidence for clients who file an appeal based on violation of parity laws. Importantly, this policy recommendation does not place undue burden on the insurer as it does not ask for any change to their system but only requests transparency around their existing practices.

\section{Disadvantages}

This proposal does not change any of the existing practices used by insurers, and there is no guarantee that increased transparency would discourage prioritizing financial self-interest. A more drastic step would be to prohibit the use of cost in determining medical necessity altogether. However, this would likely meet with strong opposition from insurers and would be difficult to implement. In addition, although this proposal would alleviate client frustration with unexplained claim denials, it is not a solution to the claim denial itself, and the client is still burdened with finding alternative care. Lastly, this proposal does not recognize the client's autonomy in determining the best treatment option for them, in consultation with their health care provider.

\section{Issue 3: Insurers do not provide sufficient information on medical necessity criteria to clients}

Currently, clients often lack sufficient information about the coverage provided by insurers to make an informed decision when choosing a plan. A recent report found that clients shopping for insurance plans through Affordable Care Act marketplaces struggled to find publicly available information on plan coverage details and that available documentation was often complex or vague (National 
Alliance on Mental Illness 2015). Given that mental illness and SUD stigma still prevents many people from seeking care in the first place, it is particularly important to remove barriers to care by providing supportive communication to help people navigate access to treatment (McGinty et al. 2018).

i. Policy recommendation: Require insurers to institute a 'cooling off' period to review plan coverage details before purchases are finalized.

During the cooling off period, the policyholder would be covered, able to fully review the terms of the policy, and able to rescind the policy without consequence. During this period, clients would be able to consult a designated state office or unit ('the Advisory Unit') regarding the plan's coverage. To ensure that clients are aware of this resource, insurers should be required to provide clients with a dedicated document summarizing their rights, noting the cooling off period, and listing the Advisory Unit's contact information. We propose that the Advisory Unit be housed in the Office of the Patient Advocate at the California Health \& Human Services Agency, which is well suited for the purpose because it is consumer-oriented and already acts as a point of convergence for the California health insurance system. The Advisory Unit should include staff specializing in behavioral health care and coverage.

\section{Advantages}

Cooling off periods are instituted in other contractual arrangements, including under the Truth in Lending Act, and other countries have instituted cooling off periods for health insurance (Health Insurance Authority 2020; Office of the Commonwealth Ombudsman 2020). This approach gives clients the time and opportunity to navigate complex documentation and pose questions before purchases are finalized. Providing this extra time is not only beneficial to individual clients but also acts as an inducement to insurers to communicate coverage

\section{References}

California Health Care Foundation. 2018. "Mental health in California: For too many, care not there." March. https://www.chcf.org/wpcontent/uploads/2018/03/MentalHealthCaliforn ia2018.pdf details more clearly and to better adhere to parity laws. In short, better-informed clients keep insurers more honest.

\section{Disadvantages}

Staffing and running the Advisory Unit would require dedicated personnel and resources. Given that multiple state agencies are already involved in overseeing health insurance in California, the addition of the Unit may seem extraneous. However, it is precisely the complex and multi-faceted nature of California's system that makes a central resource dedicated to clients necessary.

\section{Conclusions}

Mental health parity has been law in California since 1999 and at the federal level since 2008, but it has not been achieved in practice. Numerous legislative attempts to strengthen enforcement of parity have failed (Weiner 2019b). The lack of regulation around how insurers determine and assess medical necessity underlies many of the structural inequities in access to mental health and SUD treatment.

We believe the three recommendations outlined here would help rectify some of these existing parity violations. First, requiring insurers to use licensed behavioral health professionals and medical references in determining necessity criteria would ensure that criteria align with current scientific and medical standards. Second, requiring insurers to provide detailed justifications for claim denials would disincentivize insurer financial self-interest. Lastly, instituting a cooling off period before plans are finalized would improve clients' ability to comprehend their insurer's medical necessity criteria. It is high time for California to bridge the gap between coverage of behavioral and physical health care. Updating medical necessity standards for behavioral health interventions is an important step towards achieving mental health parity in California.

Dangor, Graison. 2019. "'Mental health parity' is still an elusive goal in U.S. insurance coverage." NPR. June 7. $\quad$ https://www.npr.org/sections/healthshots/2019/06/07/730404539/mental-healthparity-is-still-an-elusive-goal-in-u-s-insurancecoverage 
Davenport, Stoddard, Travis J. Gray, and Stephen P. Melek. 2019. "Addiction and mental health vs. physical health: widening disparities in network use and provider reimbursement." Milliman, Nov 20. https://www.milliman.com/en/insight/addictio n-and-mental-health-vs-physical-healthwidening-disparities-in-network-use-and-p

Erman, Erica A. and Russell A. Kolsrud. 2019. "Highlights from Wit v. United Behavioral Health." DickinsonWright, March 20. https://www.dickinsonwright.com/news-alerts/highlights-from-witunited-behavioral-health-case

Ettner, Susan L., Jessica M. Harwood, Amber Thalmayer, Michael K. Ong, Haiyong Xu, Michael J. Bresolin, Kenneth B. Wells, Chi-Hong Tseng, and Francisca Azocar. 2016. "The Mental Health Parity and Addiction Equity Act evaluation study: Impact on specialty behavioral health utilization and expenditures among "carve-out" enrollees." Journal of Health Economics 50: 131-143. https://doi.org/10.1016/i.jhealeco.2016.09.009

Health Insurance Authority, Government of Ireland. 2020. "Consumer information: Cancelling your health insurance plan." April 15. https://www.hia.ie/consumerinformation/cancelling-your-health-insuranceplan

Jarkon, Liat. 2020. "Why insurers should cover mental health care to lower costs." Fortune. February 5. https://fortune.com/2020/02/05/mentalhealth-care-coverage-insurance-costs/

The Kennedy Forum. 2020. "New bills introduced in CA to prioritize mental health and addiction treatment." January https://www.thekennedyforum.org/blog/newbills-introduced-in-ca-to-prioritize-mentalhealth-and-addiction-treatment/

McGinty, Emma, Bernice Pescosolido, Alene Kennedy Hendricks, and Colleen L. Barry. 2018. "Communication strategies to counter stigma and improve mental illness and substance use disorder policy." Psychiatric Services 69 (2): 13646. https://doi.org/10.1176/appi.ps.201700076

National Alliance on Mental Illness. 2015. "A long road ahead: Achieving true parity in mental health and substance use care." April. https://www.nami.org/SupportEducation/Publications-Reports/Public-PolicyReports/A-Long-Road-Ahead/2015ALongRoadAhead
Office of the Commonwealth Ombudsman, Government of Australia. 2020. "The right to change." April 15 https://www.ombudsman.gov.au/ data/assets/ pdf file/0020/29423/Right-to-Change-DL-FylerWeb.pdf

Office of the Governor of California. 2020. "2020-2021 Governor's Budget (Proposed)." January 10. http://www.ebudget.ca.gov/budget/202021/\#/BudgetSummary

Parity Track. 2019a. "State Report Card: California." https://pjkuploads.s3.amazonaws.com/www.paritytrack.or g/uploads/2018/09/StateReportCard 05 CA.pdf

Parity Track. 2019b. "Legislative overview in New Jersey." https://www.paritytrack.org/report/newjersey/new-jersey-legislation/

Parity Track. 2019c. "Statutory overview in Tennessee: Legislation signed into law." https://www.paritytrack.org/report/tennessee/t ennessee-law/

Rosenbaum, Sara, Brian Kamoie, D. Richard Mauery, and Brian Walitt. 2003. "Medical necessity in private health plans: Implications for behavioral health care. "Substance Abuse and Mental Health Services Administration and Center for Mental Health Services, Department of Health and Human Services. Pub. No. SMA 03-3790. https://doi.org/10.1037/e415852005-001

Roy, Anusha. 2019. "A look at Colorado's 8 new laws related to mental health." 9news. May 24. https://www.9news.com/article/news/a-lookat-colorados-8-new-laws-related-to-mental health/73-d4da707b-b5f4-41fb-bd99e11dd5b25185

Stanford Justice Advocacy Project. 2017. "Confronting California's continuing prison crisis: The prevalence and severity of mental illness among California prisoners is on the rise." Stanford University. https://law.stanford.edu/wpcontent/uploads/2017/05/Stanford-ReportFINAL.pdf

Weiner, Jocelyn. 2019a. "Breakdown: California's mental health system, explained." CalMatters, April 30. https://calmatters.org/explainers/breakdowncalifornias-mental-health-system-explained/

Weiner, Jocelyn. 2019b. “Californians aren't getting the mental health care they're legally guaranteed. Why not?" CalMatters, Dec 8. https://calmatters.org/projects/californiamental-health-care-parity/

Navita Kalair is a dentist and a recent graduate in the Dental Public Health Program at the UCSF School of Dentistry. Her interests lie in Health Services Research and she is passionate about provision of preventive dentistry in children, less privileged and special needs population. Her research focused on evaluating a school-based preventive dental health program in a Californian rural county. 
Clio Korn is a neuroscientist and science policy enthusiast. She is currently a postdoctoral scholar in the Department of Psychiatry and Behavioral Sciences at UCSF. She studies how the brain allows us to flexibly adapt to changing circumstances and what goes wrong when this ability is impaired, with the aim of guiding development of targeted therapies for the cognitive symptoms of psychiatric disorders. Clio is a member of the Leadership Team of the Science Policy Group at UCSF.

Larissa J. Maier is passionate about drug policy, mental health, and human rights. She is an advocate for universal health care and committed to ending the systemic oppression of Black people and other minority groups in the U.S. and beyond. She is a postdoctoral scholar at the UCSF Department of Clinical Pharmacy investigating how local variation in cannabis and opioid policies impact health outcomes. Larissa is a member of the Leadership Team of the Science Policy Group at UCSF. She received her PhD from the University of Zurich and worked at the United Nations Office on Drugs and Crime (UNODC) in Vienna.

Thomas Pospiech is a chemical biology $\mathrm{PhD}$ student at the University of Michigan completing his dissertation research at UCSF. His research focuses on using cryo-electron microscopy (cryo-EM) to create 3D models of proteins involved in neurodegenerative and heart disease. These models help scientists to understand how these proteins work and to create new therapies. Tom is also a member of the Leadership Team of the Science Policy Group at UCSF and serves as the Treasurer. His interests in science policy are varied and have included advocating for basic science research funding in Washington, D.C., leading advocacy workshops at UCSF's Annual LGBTQIA+ Health Forum, and co-hosting a pre-screening and bioethics fireside chat of the documentary "Human Nature".

Neiloy R. Sircar is a human rights lawyer and postdoctoral scholar with the UCSF Center for Tobacco Control Research and Education. His subject-matter expertise includes global and public health, global governance, and health in humanitarian crises. His research focus is in further developing the legal dimensions to global health and in particular human rights-based approaches to health. He is supported by National Cancer Institute Grant CA-113710.

Trisha Vaidyanathan is a neuroscience PhD student at UCSF and a passionate advocate for mental health. She is currently studying how the brain regulates sleep. Her research focuses on how an understudied population of cells in the brain called astrocytes mediates the transition between wake and sleep. The aim of this research is to develop better treatments for a range of sleep disorders, such as insomnia.

\section{Acknowledgments}

We thank Amiee Alden, Allie Jones, Ben Rubin, Michael Bedard, and the members of the Science Policy Group at UCSF for their input and support throughout our efforts to learn about and advocate for mental health care parity. 